\title{
TRANSITION AND GAP MODELS OF FOREST DYNAMICS ${ }^{1}$
}

\author{
M. F. ACEVEDO \\ Institute of Applied Sciences and Department of Geography, University of North Texas, Denton, Texas 76203 USA \\ and CESIMO, Universidad de Los Andes, Merida, Venezuela \\ D. L. URBAN ${ }^{2}$ \\ Department of Forest Sciences, Colorado State University, Fort Collins, Colorado 80523 USA \\ M. ABLAN \\ Institute of Applied Sciences and Department of Geography, University of North Texas, Denton, Texas 76203 USA \\ and CESIMO, Universidad de Los Andes, Merida, Venezuela
}

\begin{abstract}
We describe and apply a correspondence between two major modeling approaches to forest dynamics: transition markovian models and gap models or JABOWAFORET type simulators. A transition model can be derived from a gap model by defining states on the basis of species, functional roles, vertical structure, or other convenient cover types. A gap-size plot can be assigned to one state according to dominance of one of these cover types. A semi-Markov framework is used for the transition model by considering not only the transition probabilities among the states, but also the holding times in each transition. The holding times are considered to be a combination of distributed and fixed time delays. Spatial extensions are possible by considering collections of gap-size plots and the proportions of these plots occupied by each state. The advantages of this approach include: reducing simulation time, analytical guidance to the simulations, direct analytical exploration of hypothesis and the possibility of fast computation from closed-form solutions and formulae. These advantages can be useful in the simulation of landscape dynamics and of species-rich forests, as well as in designing management strategies. A preliminary application to the H. J. Andrews forest in the Oregon Cascades is presented for demonstration.

Key words: forest dynamics; functional roles; gap; GIS; H. J. Andrews forest; landscape modeling;
\end{abstract} Markov; mosaic; semi-Markov; shade tolerance; succession; transition.

\section{INTRODUCTION}

We describe a linkage between the two approaches most commonly used for modeling forest successional dynamics: markovian or transition models and JABOWA-FORET simulators or gap models. This linkage provides analytical guidance to numerical simulations and a consistent methodology to scale-up from the gap level to the stand level. This methodology is needed for applications requiring numerous simulations, as in landscape dynamics and analysis of management strategies. Further simplifications can be achieved by grouping tree species according to their functional role (e.g., regeneration and mortality), or their structural role (e.g., vertical position in the canopy), or a combination of both. These simplifications are convenient for applications to species-rich forests.

Markovian models have been used to analyze forest dynamics by simplifying the effect of environmental conditions on demography and growth (e.g., Horn 1975, Runkle 1981, and others reviewed in Usher 1992). Simulators of forest dynamics based on gap models have linked environmental parameters to demographics and growth using the JABOWA approach

${ }^{1}$ Manuscript received 29 July 1994; accepted 12 October 1994; final version received 2 December 1994.

${ }^{2}$ Present address; School of the Environment, Duke University, Durham, North Carolina 27708 USA
(Botkin et al. 1972) in cases where floristics and natural history of the species involved are available (e.g., the FORET simulator of Shugart and West 1977, and variants reviewed in Urban and Shugart 1992). Both approaches have faced limits for applications to speciesrich forests and landscape-scale analysis due to mathematical and computational difficulties induced by the increased number of species and of model plots.

The adequacy of using Markov processes and differential equations to model plant succession have been extensively discussed (e.g., Weinstein and Shugart 1983, Leps 1988, Usher 1992). The limitations include: vegetation history cannot be described by the current state (e.g., Hulst 1979b, 1980), time-inhomogeneities of the transition matrix are difficult to model (e.g., Hulst 1979b, Usher 1979, Hobbs and Legg 1983, Dorp et al. 1985), and definition of discrete states in a continuum is arbitrary (Usher 1979, 1981, 1992). However, the predictive and hypothesis-exploring capabilities of Markov models are advantageous (e.g., Runkle 1981, Usher 1981, Hobbs and Legg 1983, Scanlan and Archer 1991, Pastor et al. 1993), the potential for expanding the state description to include environmental and other biotic factors can lead to ecosystem dynamics (e.g., Hulst 1980) and the theoretical apparatus of Markov processes for calculating stochastic dynamics could be better exploited (Usher 1992). 
We will concentrate on the possibilities of including some of the vegetation history by using a semi-Markov model, which makes the transitions dependent on the time spent in a given state (Howard 1971). This type of formulation could, for example, account for the dependency on the age structure suggested as necessary by Hulst (1980) and Hobbs and Legg (1983). The semiMarkov model has been relatively less used in ecological modeling research; Marcus et al. (1979) proposed its use for compartment models, Acevedo (1981a) used its correspondence to electrical networks for modeling forest successional dynamics, Moore (1990) used its discrete formulation to relate disturbance and management strategies of vegetation dynamics, and Matis et al. (1992) applied it to shrimp migration.

Gap models have been modified and adapted to sitespecific applications but have lost generic capabilities (Urban et al. 1991, Urban and Shugart 1992). While this trend has helped us to understand the dynamics of several forests, it is still necessary to infer general behavior and formulate general hypotheses. Deriving transition models from gap models can help to extract basic features and closed-form solutions for gap models.

Modeling species-rich forests and landscape-scale forest patterns can be simplified by aggregating species according to convenient criteria. For example, species can be classified according to their light-dependence or gap-requirement characteristics, such as "pioneer" or "gap-requiring" species and "climax" or "shadetolerant" species (Acevedo 1980, 1981 $a, b$, Swaine and Whitmore 1988, Whitmore 1989). These classes have been the subject of much research and discussion (Brokaw 1982, 1985, 1987, Hubbell and Foster 1986, Brokaw and Scheiner 1989), and permit a dynamic interpretation of the forest as an ever-changing mosaic of patches cycling through gap, building, and mature phases (Watt 1947, Oldeman 1978, Whitmore 1989) or similar phases (Whittaker and Levin 1976, Bormann and Likens 1979). Even though this classification may be simplistic (Barton 1984, Hubbell and Foster 1986, Denslow 1987, Brokaw and Scheiner 1989, Canham 1989, Lieberman et al. 1989, Smith et al. 1992), it allows for a practical modeling methodology able to answer questions related to the coarse-scale dynamics of the forest mosaic.

Other examples include: definition of cover-states according to successional status for simulating large regions (Shugart et al. 1973); definition of types according to shade and drought tolerance (Smith and Huston 1989); definition of functional groups based on physiological, reproductive, and life history characteristics (Moore and Noble 1990); and identification of several tree species roles based on patterns observed in FORET-type simulations (Shugart et al. 1981, Shugart 1984, 1987). This last approach combines the gapcreating properties of trees (derived from the mortality process) with the gap-requiring properties (derived from the regeneration process), to obtain four main groups of tree species that play functional roles in the dynamics of the forest. This scheme associates size with gap creation and therefore is similar to the classification proposed by Swaine and Whitmore (1988) for tropical forests. Shugart and Urban (1989) have used simulated forests with single species representing the four roles to infer typical dynamical patterns. Transition models based on these four roles and their correspondence to gap simulators have been explored in detail by Acevedo et al. (1995a).

In the following pages, transition models using semimarkovian transitions among cover types are developed and parameterized. First, the conceptual basis of the approach is presented, emphasizing the semi-Markov transition model. Next, an example of state definition incorporating both species functional roles and canopy layers is developed. Third, the method to parameterize the transition model from the gap model is described using four functional roles as an example. Next, the basis for simulating landscape dynamics using the transition model is described. Lastly, the ideas presented in the previous sections are applied to the H. J. Andrews forest in the Western Cascades of Central Öregon; states are defined by species and vertical position in the canopy, a transition model is parameterized from a gap model, and the transition model is used to explore landscape dynamics.

\section{Markov and Semi-Markov Models}

A Markov chain describing the transitions of a forest plot among states is used to establish a semi-Markov model that also considers the different longevities and growth rates of the tree species. A gap-size forest plot is assumed to make transitions among several states defined on the basis of dominance of one of the several cover types. These types can be species, functional roles, structural roles, or a combination of both. Explicit consideration of the unoccupied gaps can be done very simply by defining them as another type. At time $t$, the total coverage in a collection of $n$ gap-size plots will be distributed among the $N$ types according to proportions $X_{i}(t)$, which should be approximately equal to the probabilities $p_{i}(t)$ that a plot is covered by type $i$ at time $t$.

The Markov chain is given by a matrix $P$ of transition probabilities. An entry $p_{\iota \jmath}$ of this matrix is associated with the transition from state $j$ to state $i$. These probabilities are defined from known relationships among the cover types or from the output of gap simulators. Examples of these methods, using four functional roles to define the states, are described in Acevedo et al. (1995a).

The steady-state derived from a Markov chain to infer the long-term forest composition fails to account for the time spent in a given state before making a transition, which is important given the different longevities and growth rates of the tree species. Therefore, 
a semi-Markov process is a more realistic model. Steady-state cover values can be analyzed under different scenarios; for example, conditions of high disturbance, conditions favoring growth of small trees, and those favoring growth of large trees (Shugart 1987). A special case of conditions of highly accentuated roles, i.e., extremes of shade-tolerance and gapcreation characteristics is analyzed in Acevedo et al. (1995a).

The holding time densities $h_{i j}$ 's, that is, the probability densities for the time spent in making the transition from type $j$ to $i$, can be conveniently defined by a gamma density (Lewis 1977, Hennesey 1980, Acevedo 1981a) $h_{t j}(t)$, which has two parameters: $d_{i j}$, and $k_{i j}$. The first one, $d_{i j}$, is a first-order rate, and the second, $k_{i j}$, is an integer representing the order of the function. For $k_{i j}>1$ the probability of making an instantaneous transition is zero. The mean and variance of this density are equal to

$$
m_{i j}=k_{l j} / d_{i j} \quad v_{i j}=k_{i j} /\left(d_{i j}\right)^{2}
$$

Statistics of interest, e.g., occupancy probabilities, entrance probabilities, transit time, etc., can be calculated from semi-Markov theory (e.g., Howard 1971). In this paper, only the formulae for the limiting behavior of the occupancy probabilities are used. These stationary probabilities represent the probabilities of finding a gap occupied by any one of the cover types.

The waiting time density, that is, the probability density of the time spent in state $j$, before making a transition to any one of the other states, can be calculated by

$$
W_{J}(t)=\sum_{i=1}^{N} p_{\imath \jmath} h_{i j}(t) \quad j=1,2, \ldots N
$$

as the sum of all the holding time densities corresponding to transitions out of state $j$. The mean waiting time in state $j$ is then the mean of $W_{j}(t)$, and denoted as $M_{\jmath}$,

$$
M_{\jmath}=\sum_{i=1}^{N} p_{\iota \jmath} m_{i j} \quad j=1,2, \ldots N
$$

or the sum of all products of the probability $p_{\imath}$ and the mean $k_{i j} / d_{i j}$ of the $h_{i j}(t)$ density. In turn, the mean time between transitions $M$ is calculated as a weighted sum of the mean waiting times in each state

$$
M=\sum_{J=1}^{N} X_{J}^{*} M_{\jmath},
$$

where the weights used in the average are the stationary proportions $X_{J}^{*}$ of the embedded chain. The steadystate occupancy probabilities, and therefore the stationary proportions $X_{j}^{* *}$ for all the types, can be calculated as

$$
X_{J}^{* *}=X_{J}^{*} M_{J} M^{-1} \quad j=1,2, \ldots, N,
$$

where $X_{j}^{* *}$ represents the fraction of the plots that will be occupied by type $j$ after a sufficiently long time has elapsed. Note that $X^{* *}$ is different from $X^{*}$ obtained from the embedded chain, demonstrating the importance of the holding time for the stationary distribution. A large value for $X_{j}^{* *}$ compared to the other types can be due to a higher value for the mean of the holding time in transitions out of state $j$, as well to a high probability of transition into state $j$.

Note that for each transition, three parameter values are needed: the rate and order for each time lag, and one transition probability. Instead of specifying the rates, it is possible to specify the orders and the means of the lags, and then use Eq. 1 to compute the rates. The dynamics can be determined by computer simulation of the mean behavior of a collection of plots. A convenient approach for the simulation is to integrate numerically the set of first-order differential equations that emulate the gamma function (Acevedo 1981a). This equivalence has been referred to as the linear chain trick (McDonald 1978), or the catenary system (Van Hulst 1979a), or pseudo-compartments (Matis et al. 1992). The transition from state $j$ to state $i$ can be considered as a sequence of transitions among intermediate states, at the rate $d_{t j}$. The transition from the state $j$ to the first intermediate state is affected by the probability $p_{y}$. All the proportions in the intermediate states of this transition are assumed to add up to the total proportion of the state $j$ undergoing that transition. Therefore, the sum over all the destination states $i$ will give the total proportion in state $j$.

For long holding times with low variance it is convenient to add a fixed time delay $f_{i j}$ to the gammadistributed time delay to obtain the holding time density (Blythe et al. 1984, Acevedo et al. 1995a). The computer simulation is more complicated because it involves the numerical integration of a set of delaydifferential equations. The mean holding time is the sum of the mean of the distributed delay and the fixed delay. Examples are given in Acevedo et al. (1995a).

\section{Functional Roles AND CANOPY VERTICAL STRUCTURE}

The definition of cover type is sufficiently general to allow the inclusion of functional roles, vertical structure, or other characteristics. For example, structural aspects can be used to characterize successional states in tropical forests (e.g., Lescure 1978, Tomlinson 1987). In this section we will combine the four functional roles discussed in the Introduction and a twolayer canopy.

The four functional roles are defined in the following manner (Shugart 1984, 1987). Role 1: gap-creating and gap-requiring, shade-intolerant trees that can grow to a large size. Role 2: gap-creating and non-gap-requiring, shade-tolerant trees that can grow to a large size. Role 3: non-gap creating and gap-requiring, shade-intolerant trees that grow to relatively small size. Role 4: non-gap-creating and non-gap-requiring, shade-tolerant trees that grow to relatively small size. Transition 
TABle 1. Definition of feasible states in the four-role, twolayer transition model.

\begin{tabular}{ccl}
\hline \hline State & Overstory & Understory \\
\hline 1 & Gap & Gap \\
2 & Gap & Role 1 \\
3 & Gap & Role 2 \\
4 & Gap & Role 3 \\
5 & Gap & Role 4 \\
6 & Role 1 & Gap \\
7 & Role 2 & Gap \\
8 & Role 1 & Role 2 \\
9 & Role 1 & Role 4 \\
10 & Role 2 & Role 2 \\
11 & Role 2 & Role 4 \\
\hline
\end{tabular}

models based on these four roles and their correspondence to gap simulators have been explored in detail by Acevedo et al. (1995a).

Since roles 3 and 4 are considered to be low stature relative to roles 1 and 2 , it is convenient to assume a two-layer structure, so that states of the model explicitly consider the relative proportions of mixed canopy. In fact, the presence of role 4 is underestimated when considering only one layer, because these small trees can never dominate an intact forest.

The states are composed of role $i$ in the upper canopy and role $j$ in the lower canopy. By combining the four roles, empty gaps, and two canopy layers we obtain a total of 11 states as defined in Table 1 . The valid transitions are derived assuming that trees can only be established in the understory and in empty positions created by mortality. The fall of large trees can create openings in both layers (from states 8, 9, 10, and 11 to state 1 ), but can also create openings in the overstory leaving already established shade-tolerant trees in the understory (from states 8 and 10 to state 3; from states 9 and 11 to state 5). According to these assumptions the following transition matrix is derived:

$P=\left[\begin{array}{cccccccccccc}0 & p_{12} & p_{13} & 1 & 1 & p_{16} & p_{17} & p_{18} & p_{19} & p_{110} & p_{111} \\ p_{21} & 0 & 0 & 0 & 0 & 0 & 0 & 0 & 0 & 0 & 0 \\ p_{31} & 0 & 0 & 0 & 0 & 0 & 0 & p_{38} & 0 & p_{310} & 0 \\ p_{41} & 0 & 0 & 0 & 0 & 0 & 0 & 0 & 0 & 0 & 0 \\ p_{51} & 0 & 0 & 0 & 0 & 0 & 0 & 0 & p_{59} & 0 & p_{511} \\ 0 & p_{62} & 0 & 0 & 0 & 0 & 0 & 0 & 0 & 0 & 0 \\ 0 & 0 & p_{73} & 0 & 0 & 0 & 0 & 0 & 0 & 0 & 0 \\ 0 & 0 & 0 & 0 & 0 & p_{86} & 0 & 0 & 0 & 0 & 0 \\ 0 & 0 & 0 & 0 & 0 & p_{96} & 0 & 0 & 0 & 0 & 0 \\ 0 & 0 & 0 & 0 & 0 & 0 & p_{107} & 0 & 0 & 0 & 0 \\ 0 & 0 & 0 & 0 & 0 & 0 & p_{117} & 0 & 0 & 0 & 0\end{array}\right]$

There are 24 transitions with non-zero probabilities and only 13 of these probabilities need to be specified. However, all 24 sets of delay parameters need to be estimated. The transition graph of this chain is shown in Fig. 1.

Parameter values are obtained by grouping the transitions into: mortality, growth and establishment. Mortality transitions are those to states having gap in both

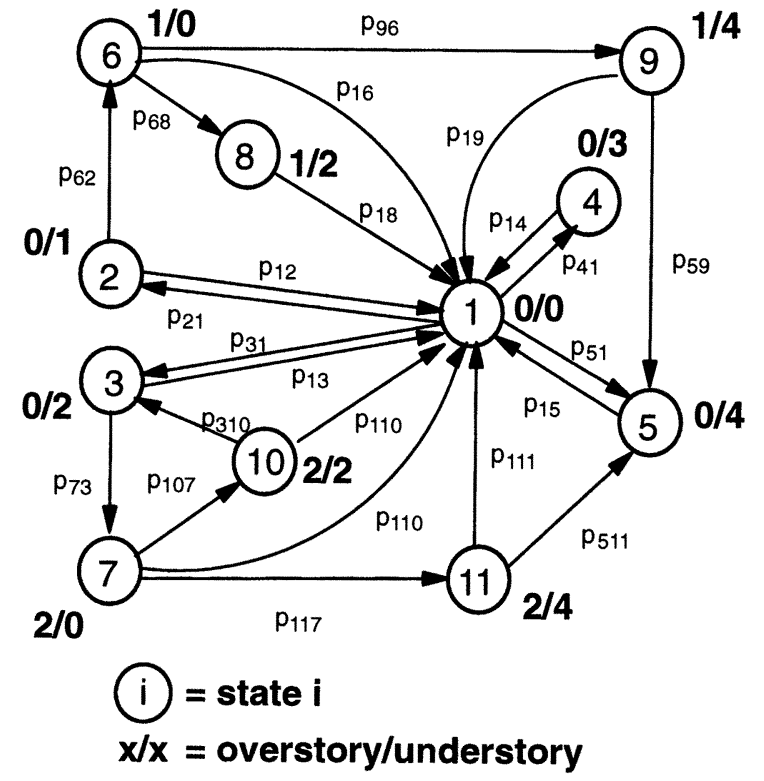

FIG. 1. A Markov model of forest dynamics based on aggregation of species in four roles and a two-layer canopy. State numbers, as defined in Table 1 , are enclosed in the circles; the transitions are shown in the transition matrix, Eq. 6 . The two-layer canopy structure is shown on the side of each circle as: role in overstory/role in understory.

layers, i.e., to state $1, p_{1}, i=2,3, \ldots, 11$; or those to states having gaps in the overstory, i.e., states 3 and $5, p_{38}, p_{310}, p_{59}, p_{511}$. Growth transitions are from those states having role $i$ in the understory to those states having the same role in the overstory, i.e., from states 2 and 3 to states 6 and 7 , respectively, $p_{62}, p_{73}$. Establishment transitions are those from states having gaps in the understory, i.e., states 1,6 , and $7, p_{21}, p_{31}, p_{41}$, $p_{51}, p_{86}, p_{96}, p_{107}, p_{117}$. For the sake of illustration we select low-mortality probabilities $p 1 i=0.1$ for $i=2$, $3,6,7,8,10$, as well as for $p_{59}, p_{511}$. The growth probabilities will then be forced to $p_{62}=p_{73}=0.9$. A high value of 0.9 is selected for $p_{19}, p_{11}, p_{38}, p_{310}$. All establishment probabilities from states having roles 1 and 2 in overstory (states 6 and 7) will be assumed to take the same value; therefore $p_{86}, p_{96}=0.45$ and $p_{107}, p_{117}$ $=0.45$. Establishment probabilities in gaps spanning both canopy layers (that is from state 1) are assumed to be high for shade-intolerant trees (roles 1 and 3), $p_{21}=p_{41}=0.45$, and low for shade-tolerant trees (roles 2 and 4$), p_{31}=p_{51}=0.05$.

Taking into account characteristics of the functional roles, we assume the values listed in Table 2 for the means, orders, and fixed latencies of the delays corresponding to these three processes. The rates are obtained using Eq. 1. The parameter values for all transitions are summarized in Table 3. A 500-yr simulation with these parameter values, for an initial condition corresponding to all plots in state 1 , yield results for the dynamics of all 11 states.

As an example of these results, Fig. 2 (top) shows 
TABLE 2. Delay density parameters for the four-role, twolayer model ( $m=$ mean in years, $k=$ order, $f=$ fixed latency in years).

\begin{tabular}{|c|c|c|c|c|c|c|c|c|c|}
\hline & \multicolumn{3}{|c|}{$\begin{array}{c}\text { Establish- } \\
\text { ment }\end{array}$} & \multicolumn{3}{|c|}{ Growth } & \multicolumn{3}{|c|}{ Mortality } \\
\hline & $m$ & $k$ & $f$ & $m$ & $k$ & $f$ & $m$ & $k$ & $f$ \\
\hline Role 1 & 3 & 2 & 2 & 30 & 2 & 10 & 10 & 4 & 100 \\
\hline Role 2 & 2 & 2 & 1 & 30 & 2 & 10 & 10 & 4 & 100 \\
\hline Role 3 & 3 & 2 & 2 & 30 & 2 & 10 & 10 & 4 & 10 \\
\hline Role 4 & 2 & 2 & 1 & 30 & 2 & 10 & 10 & 4 & 100 \\
\hline
\end{tabular}

the response of states 4,9 , and 11 . The early peak (state $4=$ Gap/Role 3) corresponds to initial colonization of gaps by small shade-intolerant trees (role 3), which subsequently decreases with time. The other two traces correspond to those states (9 and 11) having small shade-tolerant trees (role 4) in the understory. Note that these states are well represented in the canopy, even though role 4 trees are of low stature. This result demonstrates the advantage of including canopy layers in the state definition. It will be shown in the next section that excluding the vertical structure in the state definition would lead to misleading low values of role 4 .

As another example of the results, in Fig. 2 (bottom) we show three aggregated variables: the sum of all states with gap in the overstory, of all states with role 1 in the overstory, and of all states with role 2 in the overstory. Early phases of the simulation show a decrease of the proportion of gaps, followed by an in-

TABLE 3. Summary of parameter values for all transitions of the four-role, two-layer model. $p_{u p} k_{v y}$ are a-dimensional, $m_{l j}$ and $f_{l j}$ in years.

\begin{tabular}{|c|c|c|c|c|}
\hline$i, j$ & $p_{\imath}$ & $m_{\imath}$ & $k_{\imath \jmath}$ & $f_{y}$ \\
\hline \multicolumn{5}{|c|}{ Establishment } \\
\hline 2,1 & 0.45 & 3 & 2 & 2 \\
\hline 3,1 & 0.05 & 2 & 2 & 1 \\
\hline 4,1 & 0.45 & 3 & 2 & 2 \\
\hline 5,1 & 0.05 & 2 & 2 & 1 \\
\hline 8,6 & 0.45 & 2 & 2 & 1 \\
\hline 9,6 & 0.45 & 2 & 2 & 1 \\
\hline 10,7 & 0.45 & 2 & 2 & 1 \\
\hline 11,7 & 0.45 & 2 & 2 & 1 \\
\hline \multicolumn{5}{|c|}{ Growth } \\
\hline 6,2 & 0.9 & 30 & 2 & 10 \\
\hline 7,3 & 0.9 & 30 & 2 & 10 \\
\hline \multicolumn{5}{|c|}{ Mortality } \\
\hline 1,2 & 0.1 & 10 & 4 & 100 \\
\hline 1,3 & 0.1 & 10 & 4 & 100 \\
\hline 1,4 & 1 & 10 & 4 & 10 \\
\hline 1,5 & 1 & 10 & 4 & 100 \\
\hline 1,6 & 0.1 & 10 & 4 & 100 \\
\hline 1,7 & 0.1 & 10 & 4 & 100 \\
\hline 1,8 & 0.1 & 10 & 4 & 100 \\
\hline 1,9 & 0.9 & 10 & 4 & 100 \\
\hline 1,10 & 0.1 & 10 & 4 & 100 \\
\hline 1,11 & 0.9 & 10 & 4 & 100 \\
\hline 3,8 & 0.9 & 10 & 4 & 100 \\
\hline 3,10 & 0.9 & 10 & 4 & 100 \\
\hline 5,9 & 0.1 & 10 & 4 & 100 \\
\hline 5,11 & 0.1 & 10 & 4 & 100 \\
\hline
\end{tabular}

\section{Dynamics with a two layer canopy Example of some states}

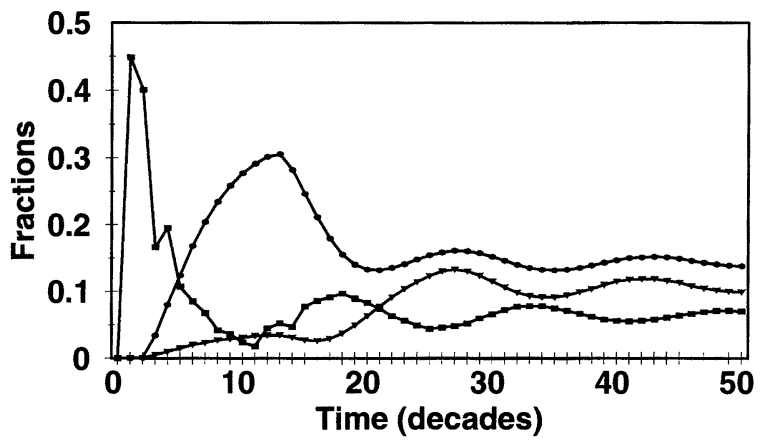

-Gap/Role3 -Role1/Role 4-Role2/Role4

Dynamics with a two layer canopy Aggregated states

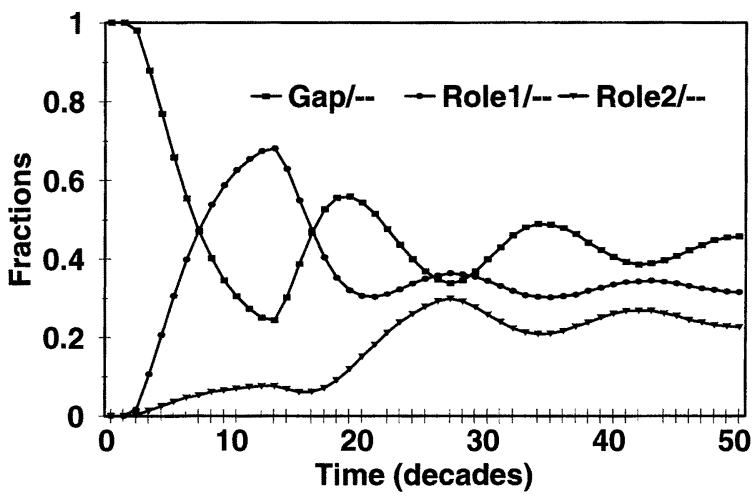

FIG. 2. Simulation results for the mean of the state probabilities according to the semi-Markov model. States defined on the basis of four roles and two canopy layers (Table 1). A complete dominance of state 1 (gap) is assumed for the initial condition. Top panel: dynamics of states 4,9 , and 11 . Bottom panel: aggregated states according to overstory dominance: gaps/any role, role $1 /$ any role, role 2 /any role.

crease of the proportion of states having role 1 in overstory and subsequent increase of those states having role 2 in overstory.

\section{PARAMETERIZING Transition MODEls From GAP MODELS}

In this section, we demonstrate how to estimate the parameters of the semi-Markov model from runs of a gap model simulator using prototypes of species that correspond to the cover types. Counting the frequency of occurrence of each transition pair and its timing allows an estimation of the transition probabilities and the holding time densities. To illustrate this procedure we summarize here the example developed in Acevedo et al. (1995a). Four species were constructed in the gap model ZELIG (Urban and Shugart 1992) to represent the four contrasting functional roles defined in the previous section. The basal area dynamics exhibit a suc- 


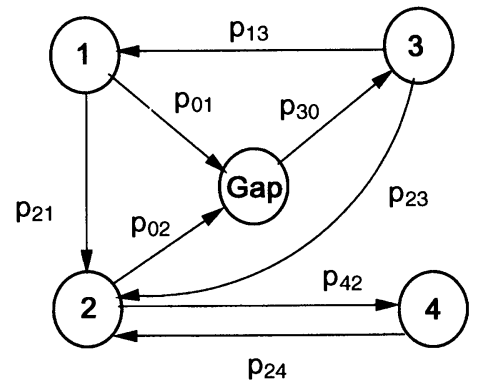

FIG. 3. Transition structure for the model as extracted from ZELIG simulations. Cycles are contained in this structure. Only the major transitions are shown.

cessional pattern over several hundred years. Role 3 asserts an early importance but quickly declines; role 1 reaches its greatest dominance in the first $100 \mathrm{yr}$, and role 2 increases steadily into the next centuries. Role 4 is the most common component of the understory in older stands, but does not have the stature to dominate the canopy. This difficulty can be removed by including a two-layer canopy as discussed in the previous section.

States were assigned to each plot by the role with the greatest basal area. A fifth state, open gap, was defined as plots with $<1 \mathrm{~m}^{2} /$ ha basal area. Better schemes can be devised using, for example, cluster analysis as demonstrated by Usher $(1981,1992)$ and Leps (1987). Using this simple classification, the relative abundance of the states shows a trend similar to the relative basal area per role. The notable exception to this is that role 4 rarely occurs because these trees, although common, are nearly always dominated by a role 1 or 2 overstory. This result indicates the convenience of a classification combining the roles and the vertical position in the canopy, as was done in the previous section.

Plot transitions are tallied in the ZELIG runs by counting the cases when the plot changes from state $i$ to state $j$, to generate a transition-count matrix for each time step. Results for 400 plots over $500 \mathrm{yr}$ of simulation with ZELIG were produced in this case. The transition graph corresponding to this structure can be seen in Fig. 3, where only the most important transitions are shown.

The time course of the frequency of occurrence of a transition from state $i$ to state $j$, allows estimation of the holding time density for the transition from $i$ to $j$. Fig. 4 illustrates some of these results. Fixed latencies can be extracted from these time traces and the estimated means of the gamma densities are obtained by subtracting the latency from the observed mean. For example, the holding time density for the transition from role 3 to 1 can be estimated, using the corresponding time trace in Fig. 4, to have the following values for the parameters: order $k_{13}=3$, mean $m_{13}=$ $50 \mathrm{yr}$, and fixed delay $f_{13}=30 \mathrm{yr}$. Following this procedure for all feasible transitions, the matrices of orders, means, and lags are obtained.

\section{Holding time densities \\ Tallied from ZELIG}

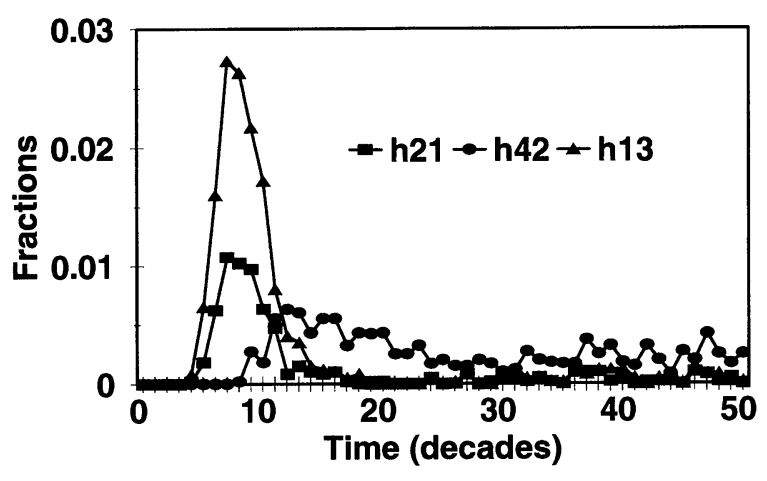

FIG. 4. Time traces of the holding time for the transitions from role 1 to role 2 , from role 2 to role 4 , and from role 3 to role 1 , as tallied from the ZELIG simulations. A $10-\mathrm{yr}$ average is shown to display the main features of the density.

The transition matrix is adjusted together with the matrix of the means to fit the semi-Markov model simulation results to the ZELIG simulation results. Using this procedure, the following matrices of parameters are obtained:

$$
\begin{aligned}
P & =\left[\begin{array}{rrrrr}
0.000 & 0.200 & 0.200 & 0.000 & 0.000 \\
0.000 & 0.000 & 0.100 & 0.875 & 0.000 \\
0.000 & 0.700 & 0.000 & 0.125 & 1.000 \\
1.000 & 0.100 & 0.000 & 0.000 & 0.000 \\
0.000 & 0.000 & 0.700 & 0.000 & 0.000
\end{array}\right] \\
k & =\left[\begin{array}{rrrrr}
0 & 5 & 5 & 0 & 0 \\
0 & 0 & 2 & 3 & 0 \\
0 & 2 & 0 & 3 & 5 \\
1 & 2 & 0 & 0 & 0 \\
0 & 0 & 5 & 0 & 0
\end{array}\right] \\
m & =\left[\begin{array}{rrrrr}
0 & 260 & 400 & 0 & 0 \\
0 & 0 & 80 & 50 & 0 \\
0 & 80 & 0 & 40 & 30 \\
1 & 40 & 0 & 0 & 0 \\
0 & 0 & 300 & 0 & 0
\end{array}\right] \mathrm{yr} \\
f & =\left[\begin{array}{rrrrr}
0 & 90 & 90 & 0 & 0 \\
0 & 0 & 0 & 30 & 0 \\
0 & 40 & 0 & 60 & 0 \\
2 & 0 & 0 & 0 & 0 \\
0 & 0 & 80 & 0 & 0
\end{array}\right] \mathrm{yr} .
\end{aligned}
$$

The stationary distribution can be calculated directly from the closed form steady-state solution (Eq. 5) as [0.0029, 0.2082, 0.6256, 0.0886, 0.0746]. Calculation of the transients by simulation exhibit the results shown 


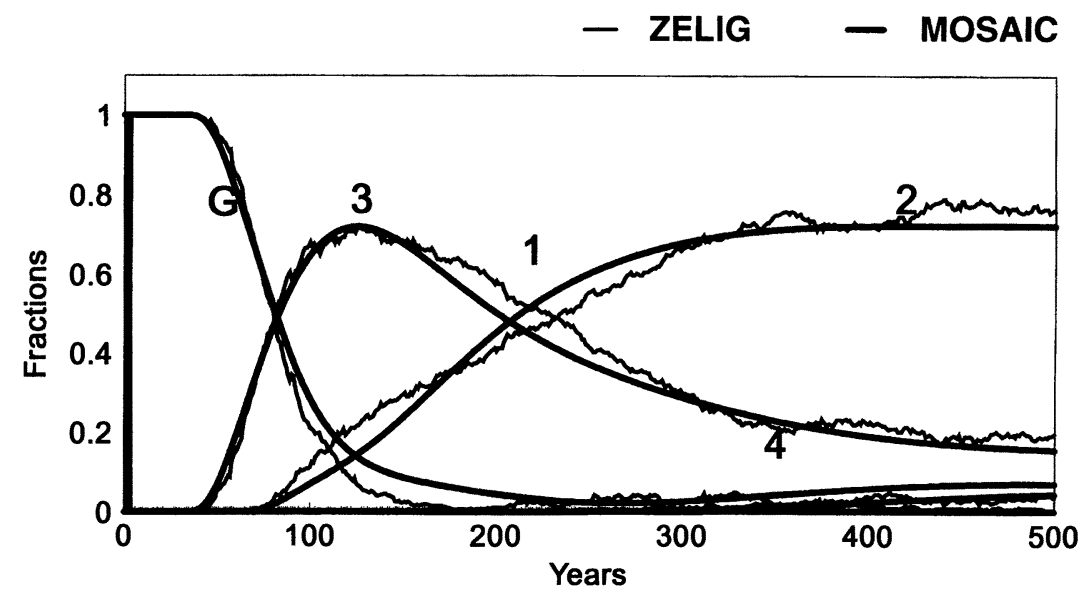

FIG. 5. Plot- or patch-type dynamics of the four different roles $(1,2,3,4)$. Comparison of semi-Markov simulations results (smooth lines) to ZELIG simulation results (fluctuating lines) illustrating the adequacy of fitting the parameters of the semi-Markov model from the ZELIG simulation, performed for 400 plots and $500 \mathrm{yr}$. Typical successional dynamics are exhibited by this simulation. $\mathrm{G}=$ gap.

in Fig. 5 together with the ZELIG simulation results. This example demonstrates the feasibility of calibrating the transition model from the ZELIG output.

\section{APPliCATION TO LANDSCAPE DYNAMICS}

This section illustrates the use of transition models to analyze forest dynamics at the landscape scale following Acevedo et al. (1995b). The transition semimarkovian model, hereafter referred to as MOSAIC, has probabilities, distributed lags, and discrete time lags estimated from simulation runs of a gap model (ZELIG) at the plot scale as described in the previous section. This parameter estimation procedure assures consistency in the change of scale. Environmental factors are stored as Geographic Information System (GIS) files and transferred to MOSAIC to adjust the parameters for simulation; values for the states at each landscape cell are generated by MOSAIC and transferred to the GIS for display and analysis.

The landscape is composed of a collection of a large number of cells (units, ecotopes, or tesserae; Naveh and Lieberman 1984). Each one of these cells is modeled as a mosaic of smaller, gap-scale plots, and its state is given as the proportion of its total area in each of several cover types. Landscape dynamics are simulated as changing proportions of within-cell cover types. The transition model is used to simulate landscape dynamics, by repetitive calculations for each cell at each time step.

Due to the Monte Carlo nature of gap-type simulators, their use for landscape applications requires multiple runs for every plot constituting a cell, whereas the transition model only requires one run per cell. For illustration, an area of 10 ha per cell would require runs of a gap model for 100 plots of 0.1 ha each, which implies a reduction by a factor of $\approx 100$ when using the semi-Markov simulation. We have developed a
MOSAIC prototype that runs in the UNIX environment and is linked to a raster-based GIS, such as GRASS (U.S. Army Corps of Engineers 1991) and the GRID module of ARC/INFO (ESRI 1992). Model output files in ASCII are converted and imported to the GIS. Results are shown in Fig. 6 for year 400 of one simulation run with random initial conditions.

Computer resource utilization depends on the number of states, the order of the delays, and the number of non-zero transition probabilities. For illustration of model performance, MOSAIC runs in $\approx 20 \mathrm{~min}$, occupying $\approx 30 \mathrm{Mb}$ of memory, when executed in a SPARC 2 workstation with $32 \mathrm{Mb}$ memory and $38 \mathrm{Mb}$ swap, for a 500-yr simulation of a landscape of 10000 ha, (1000 cells of 10 ha each), for the parameter values used in the previous section. By contrast, a 500-yr simulation run will take $\approx 3 \mathrm{~h}$ for a small watershed $(\approx 50$ ha) using the current version of ZELIG. Large numbers of cells would degrade MOSAIC's performance due to increased swapping.

The parametric dependence of successional models on environmental conditions are important for landscape applications (e.g., Weinstein and Shugart 1983, Shugart 1989; D. L. Urban and T. M. Smith, unpublished data). The interaction of these variables include slope/aspect effects on radiation; elevation effects on temperature and precipitation; and terrain effects on hydrology via topographic convergence. Terrain effects and environmental limiting factors are incorporated by assuming GIS layers containing these factors, for example: thermal effect (representing elevation and temperature), soil moisture (combining precipitation and topographical convergence), and soil fertility (representing nutrient availability). There are different methods to extract the transition model parameters from these environmental conditions. In this section we il- 

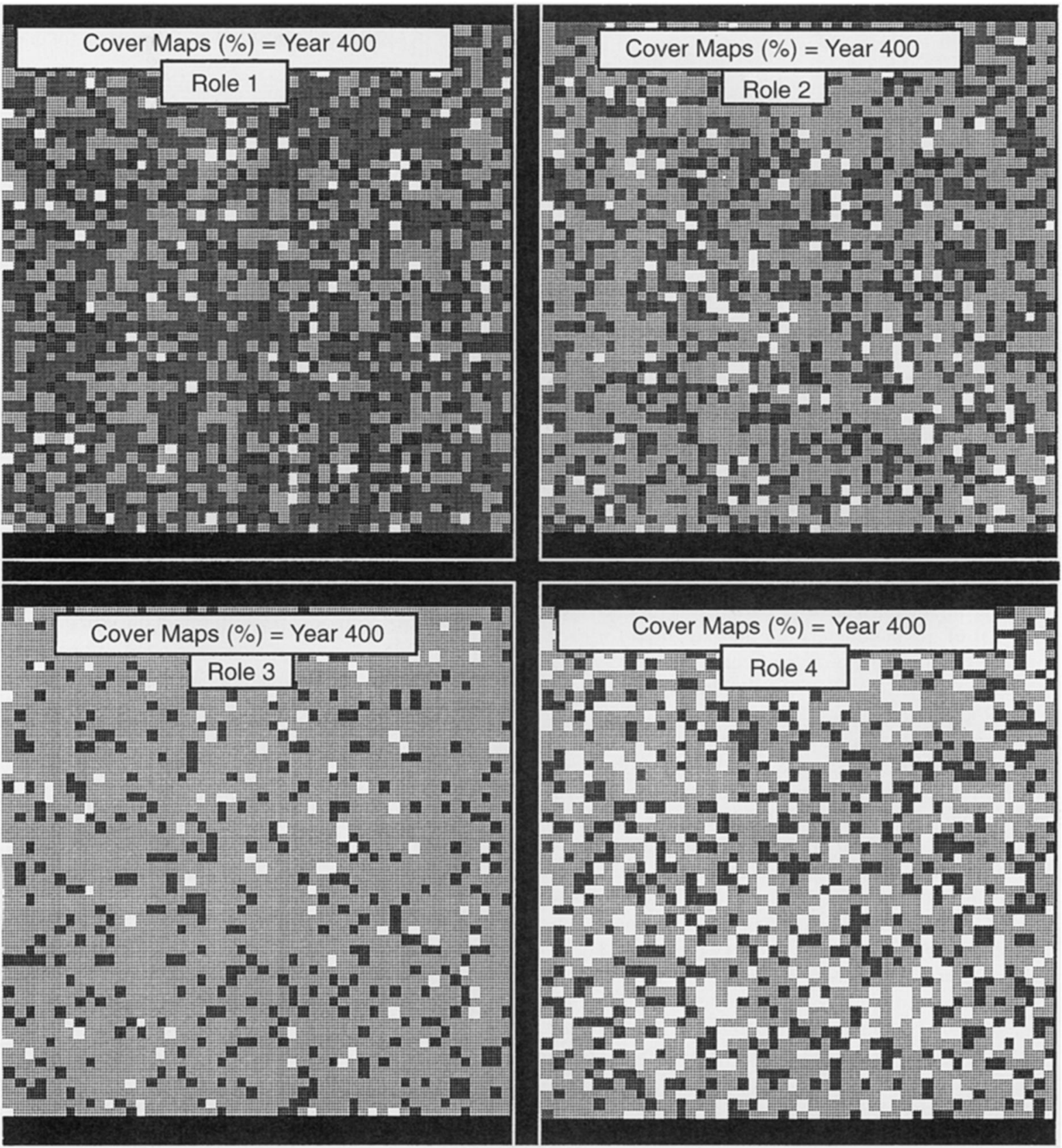

Fig. 6. Homogeneous landscape dynamics simulation results for year 400 of one simulation run with random initial conditions. Four relative cover values are shown for a hypothetical landscape of $50 \times 50=2500$ cells. Darker cells indicate larger proportion of the corresponding role.

lustrate one possible method; in the next section we will provide an example of a different method.

For every cell $k, l$ we use three variables (which take relative values between 0 and 1) stored as maps, $T_{k, l}$, $S_{k, l}$, and $F_{k, l}$ representing temperature, soil moisture, and soil fertility, respectively. For each cover type $i$ and every cell $k, l$ the environmental limiting factors (relative values between 0 and 1) are calculated, taking into account the response of the cover type to the limiting factor. A compound environmental limiting factor is then calculated for each role $i$ and every cell $k, l$. For example, a simple assumption is that the composite factor is the product of these three factors. The resulting maps for each type $i$ are then used to multiply every nominal or optimal rate $d_{j i}$ of the transition from state $i$ to all other states $j$. This is done for every transition with a non-zero probability and for each cell every year. As examples of implementing these factors, we can use expressions similar to those employed in gap models: a parabolic expression for the thermal limiting factor 


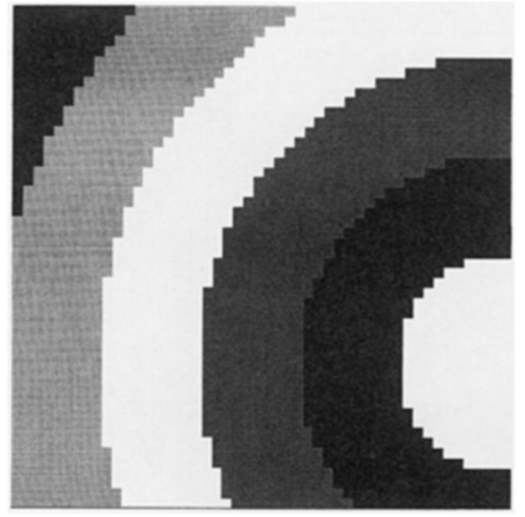

Fig. 7. A hypothetical thermal factor established to correspond to a DEM of $50 \times 50=2500$ cells of 10 ha each, with altitude values ranging from 0 to $5 \mathrm{~km}$, and temperature values from $25^{\circ}$ to $0^{\circ} \mathrm{C}$.

with maximum and minimum tolerances for each role $i$; a square-root expression for the soil moisture limiting factor parameterized by the maximum tolerable dryness for type $i$; and a quadratic expression for the soil fertility limiting factor with three parameters for each type $i$. A total of six parameters are then required for each type $i$ to compute the terrain effects.

Neighboring cell interactions should also be included to develop spatial patterns of the dynamic mosaic due to contagious disturbance (Sprugel and Bormann 1981, Knight 1987) and seed dispersal or other neighborhood effects (Turner 1987). A similar approach has been recently reported by Wissel (1992) to study the forest mosaic cycle applying the cellular automata method and considering only the dominant species.

Implementation of neighbor effects is important to account for dispersal. The layers of cover maps $X_{i}$, one for each type $i$, are available at every time step. Therefore, for every cell $k, l$ there are relative cover variables (values between 0 and 1 ) for each type $i$. Another relative variable (values between 0 and 1) $y_{k, l}^{i}$ is obtained by averaging the $X_{k, l}^{i}$ of all cells surrounding $k, l$.

$$
y_{k, l}^{i}=\sum_{q=-a}^{q=+a} \sum_{r=-a}^{r=+a} \frac{X_{k+q, l+r}^{i}}{(2 a+1)^{2}}
$$

where $a$ is an offset. For example if $a=1$, we have $(2 a+1)^{2}=9$ cells. The resulting maps $y_{i}$ (one for each type $i$ ) represent the abundance of that type around a cell. Then MOSAIC multiplies every nominal or optimal transition probability $p_{i j}$ by a correction factor

$$
p_{i j}^{*}=\frac{y_{i} p_{i j}}{\sum_{i=1}^{N} y_{i} p_{i j}}
$$

for every pair $i, j$ of states and at each cell. This correction factor assures that the sum of the new $p^{*}{ }_{i j}$ is equal to 1 .

As an illustration of the application of these ideas we construct a hypothetical landscape with altitude
TABLE 4. Maximum and minimum temperature tolerances for the hypothetical parabolic thermal response of four roles.

\begin{tabular}{lcc}
\hline \hline & $\begin{array}{c}\text { Maximum } \\
\left({ }^{\circ} \mathrm{C}\right)\end{array}$ & $\begin{array}{c}\text { Minimum } \\
\left({ }^{\circ} \mathrm{C}\right)\end{array}$ \\
\hline Role 1 & 10 & 30 \\
Role 2 & 15 & 30 \\
Role 3 & 00 & 20 \\
Role 4 & 20 & 30 \\
\hline
\end{tabular}

controlling the thermal environmental factor. Soil moisture and fertility, as well as neighbor effects, are ignored in this example. Fig. 7 illustrates the hypothetical thermal factor map which corresponds to a Digital Elevation Model (DEM), with altitude ranging from 0 to $5 \mathrm{~km}$, covering 25000 ha in $50 \times 50=2500$ cells of 10 ha each. Assuming a linear lapse rate of $5^{\circ} \mathrm{C} / \mathrm{km}$, hypothetical temperature values range from $25^{\circ}$ at the lowest sites to $0^{\circ}$ at highest sites in steps of $5^{\circ} \mathrm{C}$. All these values are hypothetical and used only for illustration. Five cover types are assumed, four functional roles and gap. The semi-Markov parameter values are the same as those derived in the previous section. The maximum and minimum thermal tolerances for the parabolic thermal response of each role are given in Table 4. Roles 1 and 2 are assumed to have optimum growth at warmer locations, whereas roles 3 and 4 are assumed to require lower temperatures. The simulation results after $500 \mathrm{yr}$ for all roles are shown in Fig. 8 and illustrate the distribution of the roles according to their thermal response. In the next section we will apply a similar method to a more realistic example.

\section{Application to H. J. AndREws Forest}

In this section we illustrate the application of the methodology developed in the previous sections to the coniferous forest in $\mathrm{H}$. J. Andrews forest, in the Oregon Cascade Mountains. This area is located at about $44^{\circ}$ $\mathrm{N}, 122^{\circ} \mathrm{W}$. For this application, three important species are considered: Douglas-fir (Pseudotsuga menziesii), western hemlock (Tsuga heterophylla) and Pacific silver fir or true fir (Abies amabilis). Cover types are generated by considering vertical position in the canopy and the age of the stand. Stand structure is a distinctive feature of different stages and age classes of the region (Cohen and Spies 1992). The following six states are defined: 1 = gap, 2 = young even-aged Douglas-fir ( $<30 \mathrm{~m}$ height), 3 = mature, even-aged Douglasfir (>30 m height), 4 = "old-growth" Douglas-fir in the upper story and western hemlock in the understory, $5=$ young true (Pacific silver) fir $(<30 \mathrm{~m}$ tall $), 6=$ mature true (Pacific silver) fir $(>30 \mathrm{~m}$ tall with an understory). These types correspond to a classification based on remote sensing (Cohen and Spies 1992), except that we added the age class for Douglas-fir and that we excluded mountain hemlock.

The ZELIG model was modified to take into account aspect, slope, and altitude. The parameters used for 


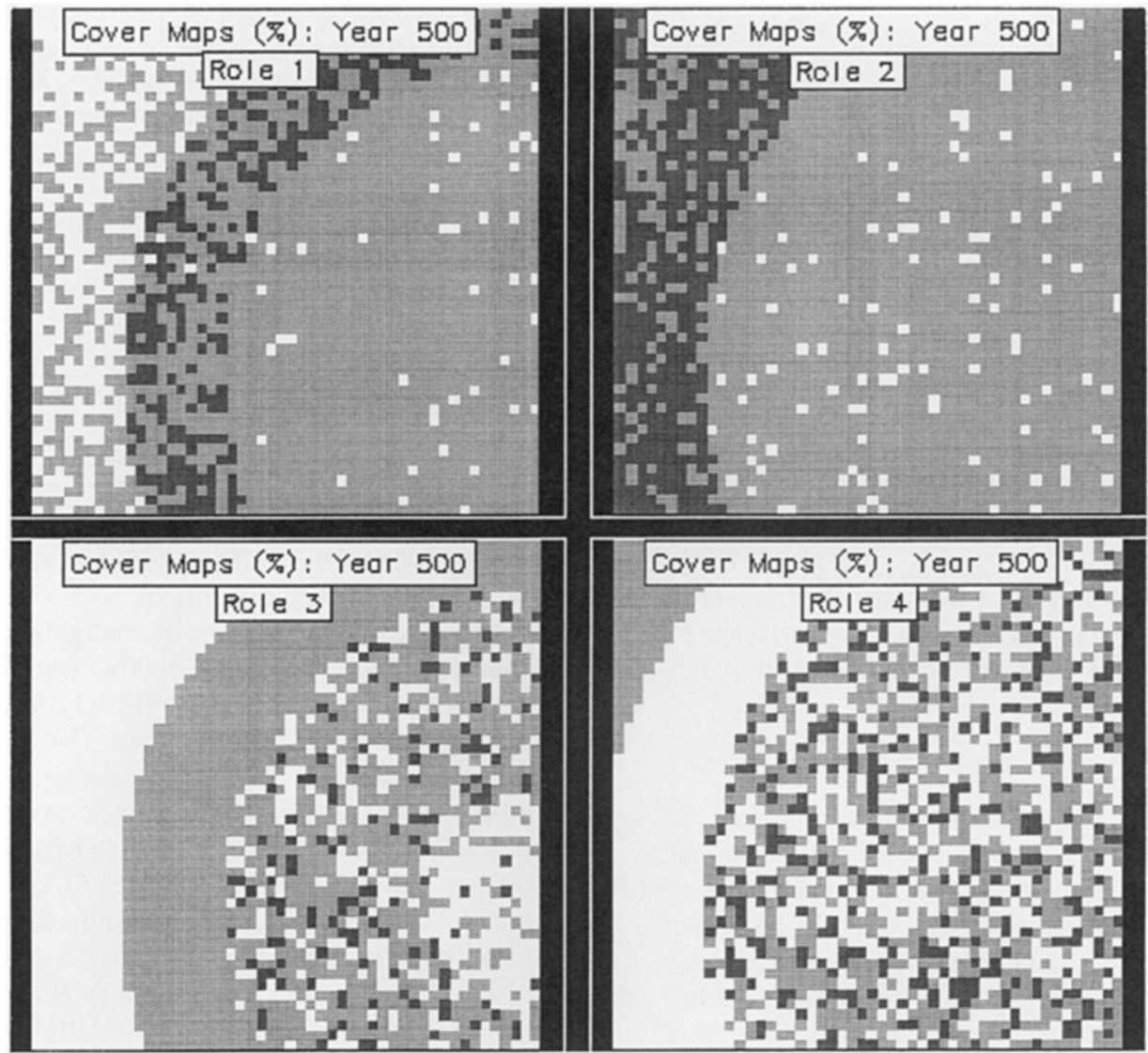

Fig. 8. Results of heterogeneous landscape dynamics simulation taking into account the environmental factor established in Fig. 7. The response of the roles is illustrated for year 500. Darker cells indicate larger proportion of the corresponding role.

each species are given in Table 5. Runs were made on a transect from 500 to $1600 \mathrm{~m}$ of altitude at $100-\mathrm{m}$ intervals. Slope was set at $50 \%$ and aspect at $180^{\circ}$ (south-facing slopes). The results of the simulation runs of the gap model at these sites were then used to estimate the structure and parameters of the transition model. The effect of temperature and precipitation is built into the results of the gap simulation model and summarized as effects of altitude.

The graph of Fig. 9 was derived on the basis of these runs. A transient pseudo-state, labeled 0 , was included in the gap phase to separate those gaps previously colonized from those gaps with bare ground at the start of the simulation. Sigmoid functions of altitude,

$$
b_{l}=\frac{1}{1+\exp \left[\left(-a l t+u_{l}\right) / s_{l}\right]},
$$

are used to account for the changes in transition probabilities and delays when moving along a gradient of altitude, here $l=1,2$ to account for two ecotones, alt $=$ altitude, $u_{l}=$ threshold, $s_{l}=$ sensitivity, all in $m$. An ecotone at $\approx 1100-1200 \mathrm{~m}$ is reported in studies of this area (Fiorella and Ripple 1993).

Some fixed latencies for transitions to state $i$ are changed linearly with the value of function $b_{l}$ as

$$
f_{i j}=\underline{f_{i j}}+a_{i} b_{l}
$$

where $f_{i j}$ is the baseline fixed latency and $a_{i}$ is a co-

TABLE 5. ZELIG parameters values for the species considered in HJA.*

\begin{tabular}{lcccccccccccc}
\hline \hline Spp. & Am & Dm & Hm & G & F & Tmin & Tmax & L & M & N & Sds & Sl \\
\hline ABam & 600 & 200 & 62.5 & 1250 & 1 & 118 & 1815 & 5 & 3 & 2 & 13.3 & 0 \\
PSme & 1100 & 300 & 84.1 & 1700 & 1 & 441 & 2411 & 2 & 4 & 2 & 13.3 & 0 \\
TShe & 500 & 225 & 63.6 & 1080 & 1 & 311 & 2480 & 5 & 3 & 2 & 13.3 & 0 \\
\hline
\end{tabular}

* Spp. $=$ species, $\mathrm{ABam}=$ Abies amabilis, $\mathrm{PSme}=$ Pseudotsuga menziesii, $\mathrm{TShe}=$ Tsuga heterophylla, Am $=$ maximum age (years), $\mathrm{Dm}=$ maximum $\mathrm{dbh}(\mathrm{cm}), \mathrm{Hm}=$ maximum height $(\mathrm{m}), \mathrm{G}=$ growth rate $\left(\mathrm{cm}^{3}\right.$ wood $/ \mathrm{m}^{2}$ leaf $), F=$ life form (generic types), $\mathrm{Tmin}=\operatorname{minimum}$ temperature tolerance (growing degree-days), $\mathrm{Tmax}=\operatorname{maximum}$ temperature tolerance (growing degree-days), $\mathrm{L}=$ shade tolerance (rank 1 to $5,1=$ very intolerant), $M=$ maximum drought tolerance (rank 1 to $5,1=$ very intolerant), $N=$ nutrient response $($ rank 1 to $3,1=$ responsive), $S d s=$ seeds, $S 1=$ sprouts. 

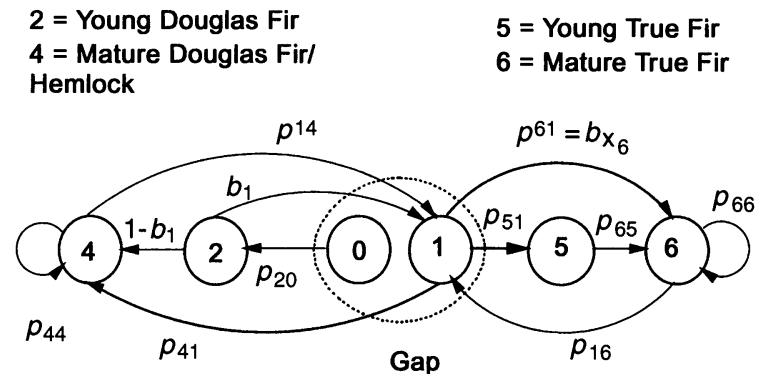

$$
p_{41}=1-b_{2}\left(1-b_{\mathrm{x}_{6}}\right)-b_{\mathrm{x}_{6}} \quad p_{51}=b_{2}\left(1-b_{\mathrm{x}_{6}}\right)
$$

FIG. 9. Transition graph for HJA forest cover types as derived from ZELIG simulation runs. Probabilities and rates are a function of altitude by using a sigmoid function.

efficient, both expressed in years. Abundance effects are accounted for by functions of cover type, e.g., by a sigmoid function of state 6 (mature true fir),

$$
b_{X_{6}}(t)=\frac{1}{1+\exp \left[\left(-X_{6}(t)+U_{6}\right) / S_{6}\right]},
$$

where $X_{6}(t)$ is the value of state 6 at time $t, U_{6}$ is a threshold, and $S_{6}$ a sensitivity, all a-dimensional.

MOSAIC parameter values estimated from ZELIG output are summarized in Table 6. Note that some of these parameters depend on elevation and cover dynamics according to Eqs. 11, 12, and 13. In turn, the parameter values for the sigmoid and linear functions given by these equations are listed in Table 7. For illustration, the temporal dynamics at 500 and $1200 \mathrm{~m}$ of altitude are displayed in Fig. 10. The results of the calibrated MOSAIC model are superimposed on these graphs for comparison.

We use the DEM that includes the HJA forest as illustrated in Fig. 11 with altitude ranging from 400 to $1617 \mathrm{~m}$. This map corresponds to an area of $\approx 18000$ ha, from $44^{\circ} 11^{\prime} 20.4^{\prime \prime} \mathrm{N}$ to $44^{\circ} 17^{\prime} 15.9^{\prime \prime} \mathrm{N}$ and from $122^{\circ} 5^{\prime} 1.5^{\prime \prime} \mathrm{W}$ to $122^{\circ} 17^{\prime} 15.4^{\prime \prime} \mathrm{W}$. The DEM has $371 \times$ $539 \approx 200000$ cells of $30 \times 30 \mathrm{~m}$. For a preliminary demonstration of MOSAIC operating at plot-size scale, we selected a small sector of Fig. 11 , from $\approx 44^{\circ} 12^{\prime} \mathrm{N}$ to $44^{\circ} 13^{\prime} \mathrm{N}$ and $122^{\circ} 8^{\prime} \mathrm{W}$ to $122^{\circ} 9^{\prime} \mathrm{W}$ (Fig. 12), with altitude ranging from 846 to $1573 \mathrm{~m}$. A total of $56 \times$ $59=3304$ landscape cells of $900 \mathrm{~m}^{2}(0.09 \mathrm{ha})$ cover an area of $\approx 300$ ha or $1.6 \%$ of total area in Fig. 11 . This relatively small landscape size could also be simulated using ZELIG, but we use MOSAIC to illustrate the first step of the scaling-up procedure. Even at this small landscape size, MOSAIC offers the advantage of closed form solutions. The results at the end of the simulation run are shown in Fig. 13 for cover type 6, corresponding to mature true fir, which illustrates the effect of altitude on the distribution of this cover type. A noticeable ecotone is indeed displayed at $\approx 1100$ $1200 \mathrm{~m}$ altitude due to the value of $1050 \mathrm{~m}$ selected for $u_{2}$.

To illustrate the scaling-up procedure we now modify
TABLE 6. Summary of MOSAIC parameter values estimated from ZELIG output. $p_{\imath}, k_{\imath \jmath}$ are a-dimensional, $m_{i j}$ and $f_{i j}$ in years. Some values depend on $b_{1}$ and $b_{x_{6}}$ functions.

\begin{tabular}{clrrc}
\hline \hline$i, j$ & \multicolumn{1}{c}{$p_{i j}$} & $m_{i j}$ & $k_{i j}$ & $f_{\imath \jmath}$ \\
\hline 2,0 & 1 & 2 & 2 & $10+a_{2} b_{1}$ \\
1,2 & $b_{1}$ & 3 & 1 & $59+a_{1} b_{1}$ \\
4,2 & $1-b_{1}$ & 10 & 4 & 77 \\
4,1 & $1-b_{2}\left(1-b_{X_{6}}\right)-b_{X_{6}}$ & 10 & 1 & $10+a_{4} b_{1}$ \\
5,1 & $b_{2}\left(1-b_{X_{6}}\right)$ & 8 & 1 & 20 \\
6,1 & $b_{X_{6}}$ & 10 & 1 & 0 \\
1,4 & 0.25 & 200 & 1 & 0 \\
4,4 & 0.75 & 10 & 1 & 0 \\
6,5 & 1 & 2 & 2 & 50 \\
1,6 & 0.35 & 400 & 1 & 0 \\
6,6 & 0.65 & 5 & 1 & 0 \\
\hline
\end{tabular}

the whole area of the DEM that contains the HJA forest (Fig. 11) by aggregating cells of $30 \times 30 \mathrm{~m}$ into cells of larger size. The elevations of $n$ neighboring cells are combined using the nearest neighbor option in the RESAMPLE command of GRID (ESRI 1992) to obtain the altitude of one aggregated cell. For demonstration we used $n=3$ and 5 . In the first case $(n=3)$, the cells are $90 \times 90 \mathrm{~m}\left(8100 \mathrm{~m}^{2}\right.$ or $\left.0.81 \mathrm{ha}\right)$, and the DEM of Fig. 11 is converted into an aggregated DEM having $371 / 3 \approx 123$ rows and $539 / 3 \approx 179$ columns, for $a$ total of $\approx 22000$ cells, or a 10 -fold reduction in the number of cells, with altitude ranging from 400 to 1612 $\mathrm{m}$. In the second case $(n=5)$, the cells are $150 \times 150$ $\mathrm{m}\left(22500 \mathrm{~m}^{2}\right.$ or $\left.2.25 \mathrm{ha}\right)$, and the DEM of Fig. 11 is converted into the aggregated DEM of Fig. 14, having $371 / 5 \approx 74$ rows and $539 / 3 \approx 108$ columns, for a total of $\approx 8000$ cells. Of course, some loss of resolution is observed. Altitude of aggregated cells now ranges from 400 to $1600 \mathrm{~m}$.

We now use the aggregated DEM for demonstration runs of MOSAIC for all 18000 ha at different cell sizes. A 500-yr simulation run on a SPARC 2, with $48 \mathrm{Mb}$ RAM and $1 \mathrm{~Gb}$ SWAP, takes $\approx 36 \mathrm{~h}$ for cells of $90 \times$ $90 \mathrm{~m}$ and $12 \mathrm{~h}$ for cells of $150 \times 150 \mathrm{~m}$. As an example of this last cell size, Fig. 15a and b show MOSAIC simulation results at the end of the 500-yr run for cover types 4 and 6, mature Douglas-fir/hemlock and mature true fir, respectively. Distribution of these types according to altitude is noticeable.

In order to further reduce simulation time, we can either select a smaller sector of the aggregated DEM and run MOSAIC only in this sector, or we can maintain a large area and proceed with further aggregation. Of course, the desired approach will depend on the resolution required to answer the questions to be asked from the model. In the second case, we would be interested

TABLE 7. Parameter values for sigmoid functions and linear functions.

\begin{tabular}{ccccccccc}
\hline \hline $\begin{array}{c}u_{1} \\
(\mathrm{~m})\end{array}$ & $\begin{array}{c}s_{1} \\
(\mathrm{~m})\end{array}$ & $\begin{array}{c}u_{2} \\
(\mathrm{~m})\end{array}$ & $\begin{array}{c}s_{2} \\
(\mathrm{~m})\end{array}$ & $\begin{array}{c}U_{6} \\
\text { (adim.) }\end{array}$ & $\begin{array}{c}S_{6} \\
\text { (adim. })\end{array}$ & $\begin{array}{c}a_{1} \\
(\mathrm{yr})\end{array}$ & $\begin{array}{c}a_{2} \\
(\mathrm{yr})\end{array}$ & $\begin{array}{c}a_{4} \\
(\mathrm{yr})\end{array}$ \\
\hline 550 & 25 & 1050 & 20 & 0.1 & 0.001 & -0.5 & -5.5 & 1.5 \\
\hline
\end{tabular}


1=Gap, 2=DFir 4 = DFir/Hemlock
Dynamics at $\mathbf{5 0 0} \mathrm{m}$

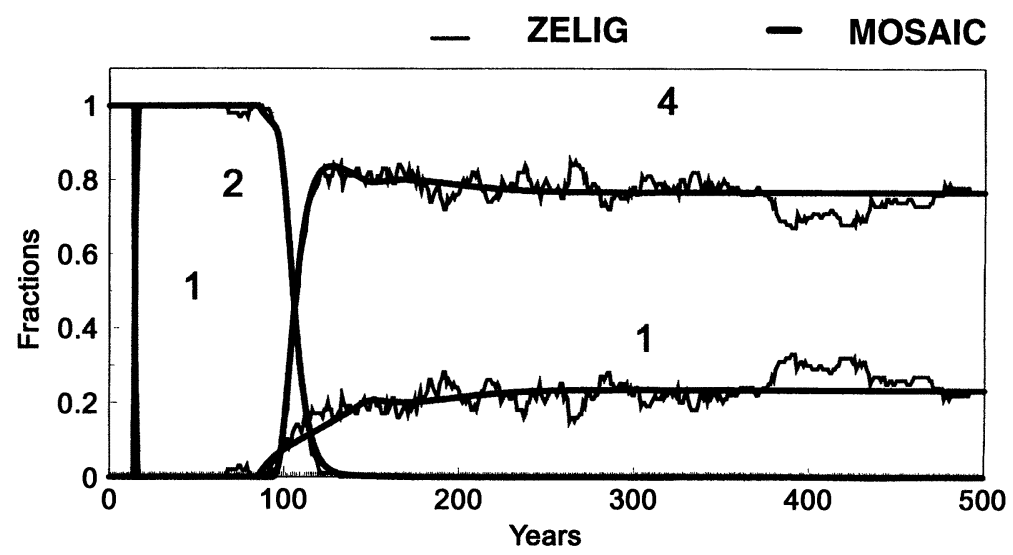

1=Gap,2=DFir 4=DFir/Hemlock $5=$ YTFir, $6=$ MTfir

Dynamics at $1200 \mathrm{~m}$

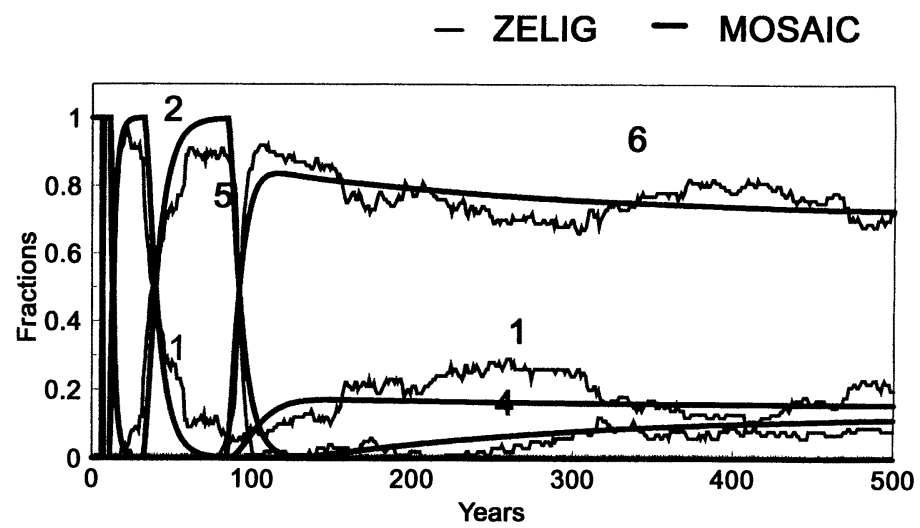

FIG. 10. Calibration of MOSAIC model using results of ZELIG runs at different altitudes at HJA. The dynamics at (top panel) $500 \mathrm{~m}$ and (bottom panel) $1200 \mathrm{~m}$ are shown for illustration.

only in coarse-scale dynamics; for example, using an aggregated cell made up of 49 neighboring cells of 210 $\times 210 \mathrm{~m}=44100 \mathrm{~m}^{2}$ or $4.41 \mathrm{ha}$, a modified DEM (Fig. 16) of $371 / 7 \approx 53$ rows and $539 / 7 \approx 77$ columns, or $\approx 4000$ cells, is obtained. Altitude ranges from 402 to $1601 \mathrm{~m}$. The simulation time required for a $500-\mathrm{yr}$ run is now reduced to $\approx 1.67 \mathrm{~h}$ on the same machine. Fig. 17 shows the results for cover types 4 and 6 . Broad features of distribution with altitude are still noticeable, but not so much resolution is obtained in the ecotone areas and the valleys.

This application is presented for demonstration purposes only. Calibration using ZELIG output was performed only at south-facing and 50\% slopes for only one soil type. Improvements in model performance are expected by calibrating for different environmental conditions.

\section{Discussion AND CONCLUSIONS}

The linkage developed in this paper between the two most widely used modeling approaches to forest dynamics, transition markovian models and JABOWAtype simulators, has several advantages. In addition to simplifying the simulations, the existing theoretical apparatus for Markov and semi-Markov processes can be very helpful to provide analytical guidance to the simulations and provide fast, direct exploration of hypotheses from closed-form solutions and formulae. A semi-Markov transition model offers flexibility in scale and simplicity of analysis.

There are many ways of defining the states or cover types, and this definition is an important part of designing a transition model. Functional roles can be defined according to the requirement of canopy gaps for regeneration and the capacity for opening canopy gaps 


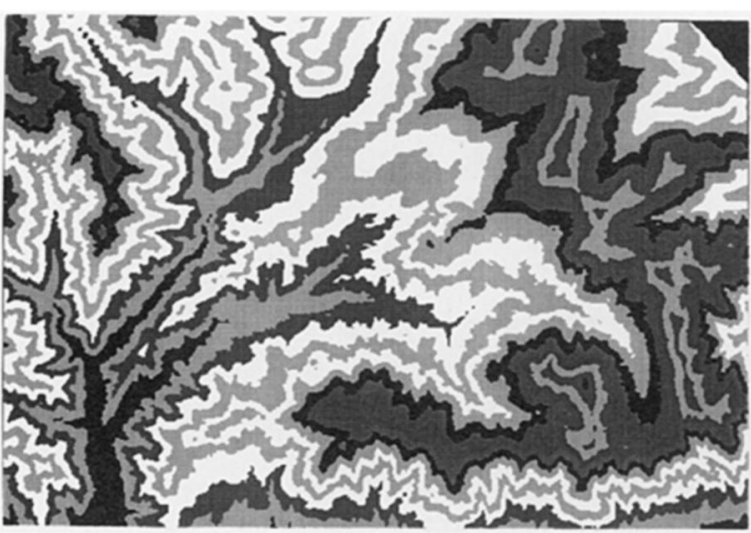

Fig. 11. Digital Elevation Model (DEM) of HJA forest covering $\approx 18000$ ha, from $44^{\circ} 11^{\prime} 20.4^{\prime \prime} \mathrm{N}$ to $44^{\circ} 17^{\prime} 15.9^{\prime \prime} \mathrm{N}$ and from $122^{\circ} 5^{\prime} 1.5^{\prime \prime} \mathrm{W}$ to $122^{\circ} 17^{\prime} 15.4^{\prime \prime} \mathrm{W}$. The DEM has 371 $\times 539 \approx 200000$ cells of $30 \times 30 \mathrm{~m}$. Altitude ranges from 400 to $1617 \mathrm{~m}$.

upon death. For consideration of structure, states can be defined as a combination of layer and role, yielding a more detailed and realistic model.

Other criteria to group the tree species into types could be used, such as those derived from architecture or morphology following the Hallé prototypes, or those related to climatic conditions (e.g., Box 1981, Woodward 1987). However, the types analyzed in this paper are easily characterized from the well-studied JABOWA-type simulators, and have the advantage of being related to the dynamic concept of the forest cycle.

Long-term trends cannot be investigated by the transition probability matrix alone; the time delays or holding times in the transitions are important in determining the stationary distribution, as well as the transients following a disturbance. Defining the delays as a chain of first-order processes has the advantage of facilitating computer simulation, and of introducing intermediate

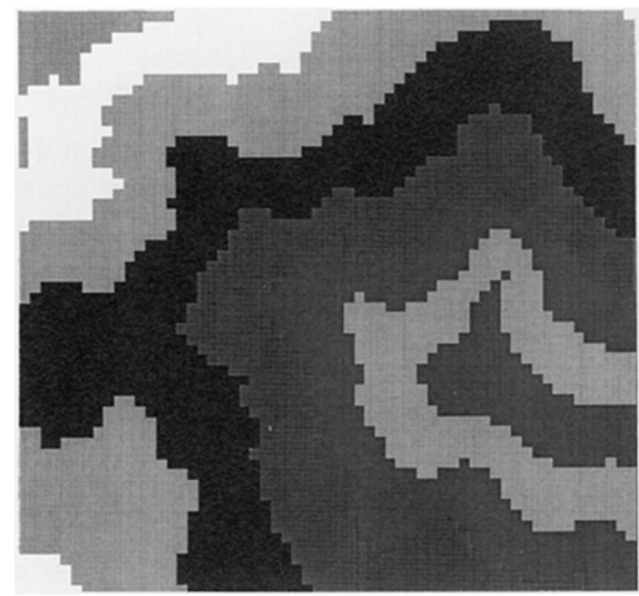

FIG. 12. Digital Elevation Model (DEM) of a small sector of HJA forest, from $\approx 44^{\circ} 12^{\prime} \mathrm{N}$ to $44^{\circ} 13^{\prime} \mathrm{N}$ and $122^{\circ} 8^{\prime} \mathrm{W}$ to $122^{\circ} 9^{\prime} \mathrm{W}$, selected for demonstration run of $56 \times 59$ cells of size $30 \times 30 \mathrm{~m}$. Altitude ranges from 846 to $1573 \mathrm{~m}$.

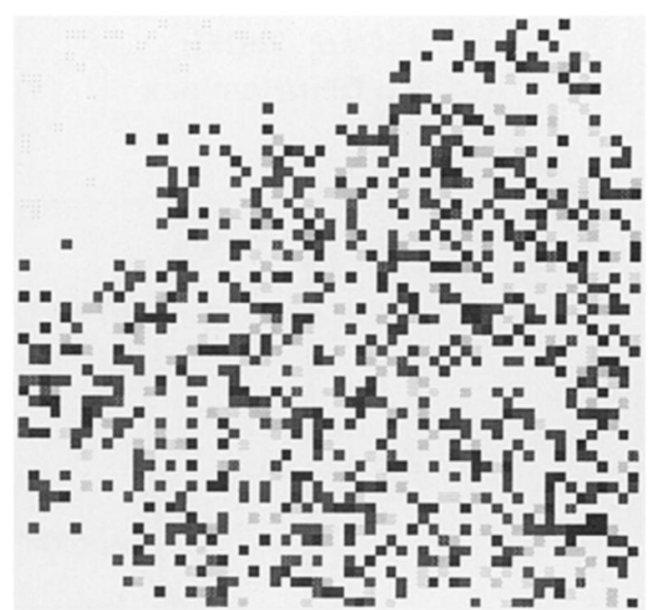

FIG. 13. MOSAIC results at end of simulation run of 500 $y r$, at cell size of $30 \times 30 \mathrm{~m}$, for mature true fir in the selected sector of HJA forest displayed in Fig. 12. Distribution of this cover type according to altitude is illustrated.

states that could potentially be used as size classes. These age classes could be used to infer dbh structure.

The establishment and mortality patterns of the JABOWA and FORET type of simulators are captured in the transition model in terms of transition probabilities among different species roles. Growth and aging rates are accounted for by distributed and fixed time delays associated with the transitions.

Once the parameters of the transition model are obtained from detailed simulations using a JABOWAtype simulator, the transition mode' can be used to run a simplified simulation of the dynamics in those cases when a large number of simulation runs are required, e.g., landscape applications, or when a large number of parameters are required, e.g., for species-rich forests.

The potential of the transition model to simulate landscape dynamics is enhanced by linking it with a GIS. The parameters, probabilities, and delays are

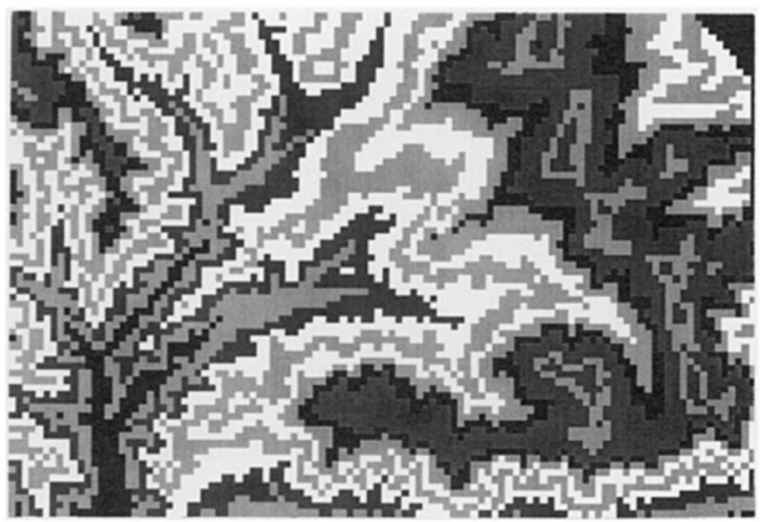

Fig. 14. Modified DEM for HJA by aggregating cells of $30 \times 30 \mathrm{~m}$ into cells of $150 \times 150 \mathrm{~m}$. The altitudes of 25 neighboring cells are combined to obtain the altitude of one aggregated cell. Altitude ranges from 400 to $1600 \mathrm{~m}$. 

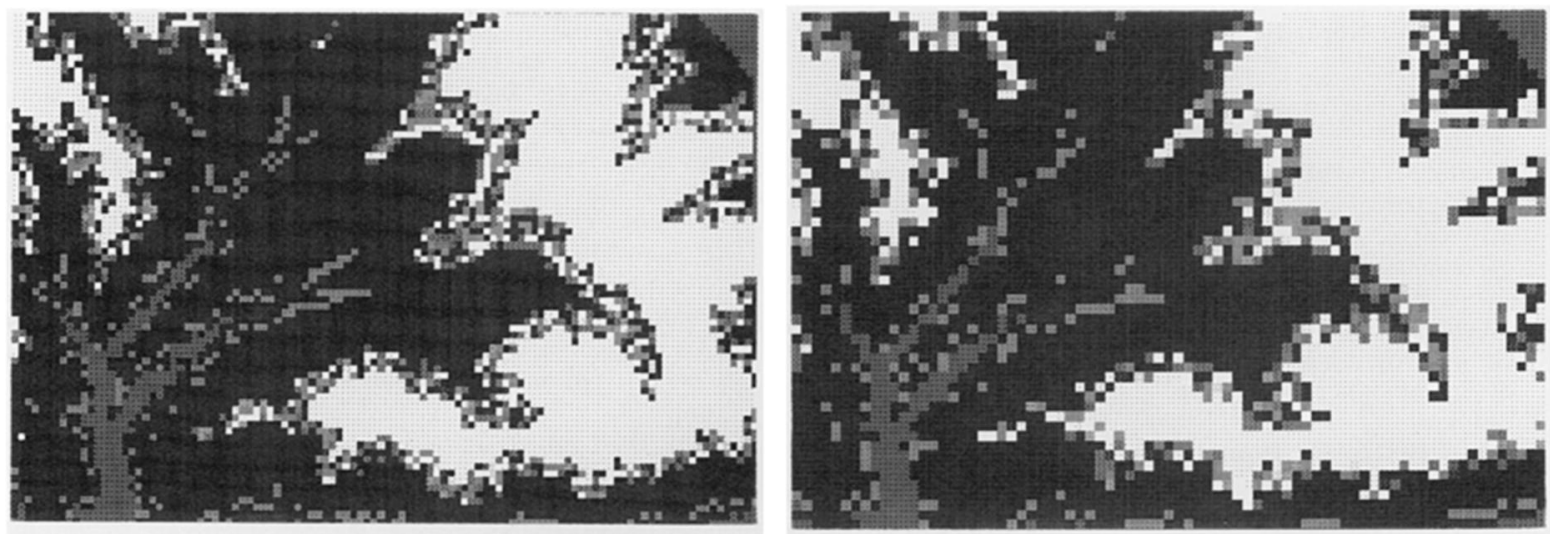
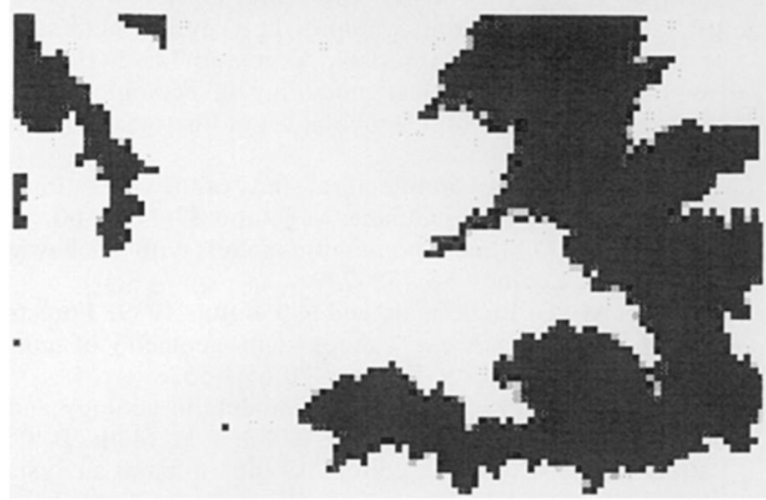

Fig. 15. Results at the end of simulation demonstration run of MOSAIC, at a cell size of $150 \times 150 \mathrm{~m}$, for the aggregated DEM of Fig. 14. Top panel: cover type 4. Bottom panel: cover type 6. Distribution of these types according to altitude is illustrated.

made functions of soil moisture, slope, fertility, and other environmental conditions of each landscape cell.

Cell interactions are included to develop spatial patterns of the dynamic mosaic (Bormann and Likens 1979, Knight 1987), as for example wind-induced waves (Sprugel and Bormann 1981). A similar approach has been recently reported by Wissel (1992) to

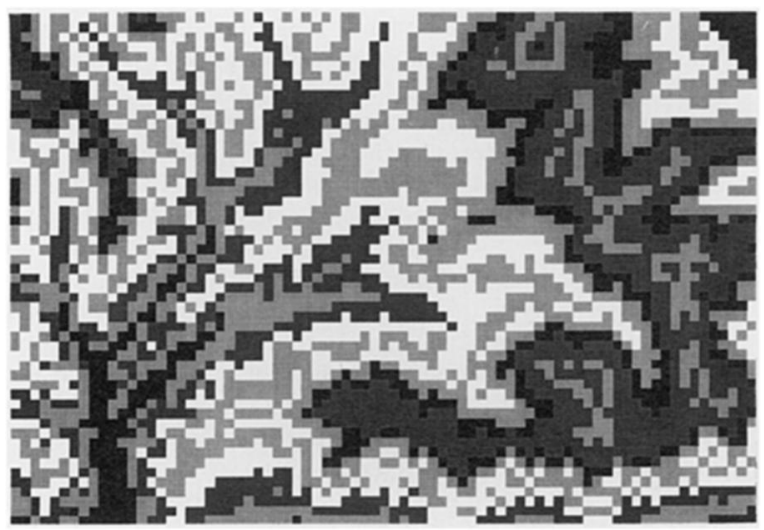

FIG. 16. Modified DEM for HJA by aggregating cells of $30 \times 30 \mathrm{~m}$ into cells of $210 \times 210 \mathrm{~m}$. The altitudes of 49 neighboring cells are combined to obtain the altitude of one aggregated cell. Altitude range from 402 to $1601 \mathrm{~m}$.

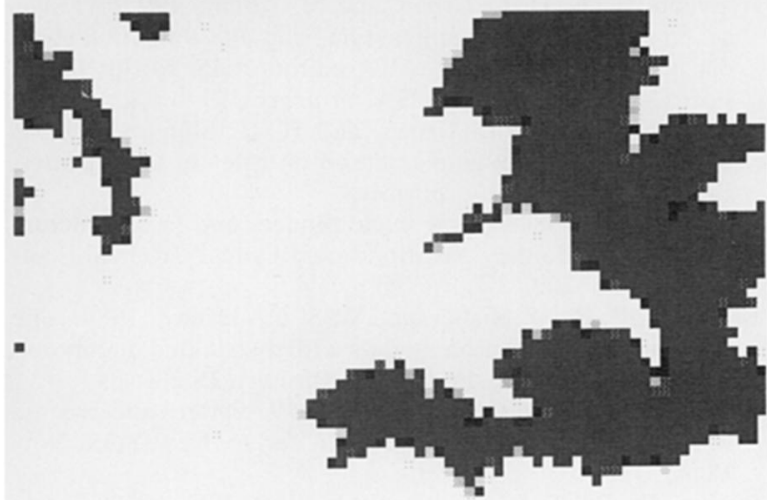

FIG. 17. Results at the end of simulation demonstration run of MOSAIC, at a cell size of $210 \times 210 \mathrm{~m}$, for the aggregated DEM of Fig. 14. Top panel: cover type 4 . Bottom panel: cover type 6. Distribution of these types according to altitude is illustrated.

study the forest mosaic cycle applying the cellular automata method and considering only the dominant species.

The approach we have presented here can play a role in understanding ecosystems dynamics at the landscape scale. Questions at this large scale can be addressed by the transition model while maintaining a consistent conceptual and empirical basis with finer scale ecological detail through its correspondence with gap models. Consistency across scales is much needed in landscape ecology (Meentemeyer and Box 1987, Risser 1987).

This framework provides new capabilities for land use and management strategies by making it possible to obtain fast simulation results for the interaction of time and space heterogeneity of land management, natural disturbances, and successional dynamics.

\section{ACKNOWLEDGMENTS}

We want to express our gratitude to $H$. H. Shugart, University of Virginia, for the stimulating impetus to the concept of functional roles and their linkage to transition models. We also wish to thank J. Pastor, University of Minnesota, D. Schimel, UCAR and University of Colorado, and an anonymous reviewer for very valuable comments on a preceding version of this paper. We are also very grateful to $B$. Hunter, 
University of North Texas, for providing great help with the GIS work.

\section{LiteratURE CiTED}

Acevedo, M. F. 1980. Tropical rain forest dynamics: a simple mathematical model. Pages 219-227 in J. I. Furtado, editor. Tropical ecology and development. International Society of Tropical Ecology, Kuala Lumpur, Malaysia.

1981a. Electrical network simulation of tropical forest successional dynamics. Pages 883-892 in D. M. Dubois, editor. Progress in ecological engineering and management by mathematical modeling. Editions CEBEDOC, Liege, Belgium.

- 1981b. On Horn's markovian model of forest succession with particular reference to tropical forests. Theoretical Population Biology 19(2):230-250.

Acevedo, M. F., D. L. Urban, and M. Ablan. 1995b. Landscape scale forest dynamics: GIS, gap and transition models. In M. F. Goodchild et al., editors. GIS World Books, Fort Collins, Colorado, USA, in press.

Acevedo, M. F., D. L. Urban, and H. H. Shugart. $1995 a$. Models of forest dynamics based on roles of tree species. Ecological Modelling, in press.

Barton A. M. 1984. Neotropical pioneer and shade-tolerant tree species: do they partition treefall gaps? Tropical Ecology 25:196-202.

Blythe, S. P., R. M. Nisbet, and W. S. C. Gurney. 1984. The dynamics of population models with distributed maturation periods. Theoretical Population Biology 25:289-311.

Bormann, F. H., and G. G. Likens. 1979. Pattern and process in a forested ecosystem. Springer-Verlag, New York, New York, USA.

Botkin, D. B., J. F. Janak, and J. R. Wallis. 1972. Some ecological consequences of a model of forest growth. Journal of Ecology 60:849-873.

Box, E. O. 1981. Macroclimate and plant forms: an introduction to predictive modelling in phytogeography. Junk, The Hague, The Netherlands.

Brokaw, N. V. L. 1982. Treefalls: frequency, timing, and consequences. Pages 101-108 in E. G. Leigh, A. S. Rand, and D. M. Windsor, editors. The ecology of a tropical forest, seasonal rhythms and long term changes. Smithsonian Institution Press, Washington, D.C., USA.

- 1985. Gap-phase regeneration in a tropical forest Ecology 66:682-687.

1987. Gap-phase regeneration of three pioneer tree species in a tropical forest. Journal of Ecology 75:9-19.

Brokaw, N. V. L., and S. M. Scheiner. 1989. Species composition in gaps and structure of a tropical forest. Ecology 70:538-541.

Canham, C. D. 1989. Different responses to gaps among shade-tolerant tree species. Ecology 70:548-550.

Cohen, W. B., and T. A. Spies. 1992. Estimating structural attributes of Douglas-fir/western hemlock forest stands from Landsat and SPOT imagery. Remote Sensing of Environment 4(1): 1-18.

Denslow, J. S. 1987. Tropical rainforest gaps and tree species diversity. Annual Review of Ecology and Systematics 18: 431-451.

ESRI. 1992. ARC/INFO user's guide. Cell-based modeling with GRID. Environmental Systems Research Institute, Redlands, California, USA.

Fiorella, M., and W. J. Ripple. 1993. Determining successional stage of temperate coniferous forests with landsat satellite data. Photogrammetric Engineering and Remote Sensing 59(2):239-246.

Hennessey, J. C. 1980. An age dependent, absorbing semimarkov model of work histories of the disabled. Mathematical Biosciences 51:283-304.

Hobbs, R. J., and C. J. Legg. 1983. Markov models and initial floristic composition in heathland vegetation dynamics. Vegetatio 56:31-43.

Horn, H. S. 1975. Markovian properties of forest succession. Pages 196-211 in M. Cody and J. Diamond, editors. Ecology and evolution of communities. Harvard University Press, Cambridge, Massachusetts, USA.

Howard, R. A. 1971. Dynamic probabilistic systems. Volume II. Semi-Markov and decision processes. Wiley, New York, New York, USA.

Hubbell, S. P., and R. B. Foster. 1986. Canopy gaps and the dynamics of a neotropical forest. Pages 77-96 in M. J. Crawley, editor. Plant ecology. Blackwell Scientific, Oxford, UK

Knight, D. H. 1987. Parasites, lightning, and the vegetation mosaic in wilderness landscapes. Pages $59-83$ in M. G. Turner, editor. Landscape heterogeneity and disturbance. Springer-Verlag, New York, New York, USA

Leps, J. 1987. Vegetation dynamics in early old field succession: a quantitative approach. Vegetatio 72:95-102. - 1988. Mathematical modelling of ecological succession-a review. Folia Geobotanica et Phytotaxonomica 23:79-94.

Lescure, J. P. 1978. An architectural study of the vegetation's regeneration in French Guiana. Vegetatio 37(1):53-60.

Lewis, E. R. 1977. Linear population models with stochastic time delays. Ecology 58:738-749.

Lieberman, M., D. Lieberman, and R. Peralta. 1989. Forests are not just Swiss cheese: canopy stereogeometry of nongaps in tropical forests. Ecology 70:550-552.

Marcus, A. H. 1979. Semi-Markov models in ecology and environmental health. Pages 211-278 in J. H. Matis, B. C. Patten, and G. C. White, editors. Compartmental analysis of ecosystem models. International Cooperative Publishing House, Fairland, Maryland, USA.

Matis, J. H., W. E. Grant, and T. H. Miller. 1992. A semiMarkov process model for migration of marine shrimp. Ecological Modelling 60:167-184.

McDonald, N. 1978. Time lags in biological models. Springer-Verlag, New York, New York, USA.

Meentemeyer, V., and E. O. Box. 1987. Scale effects in landscape studies. Pages 15-34 in M. G. Turner, editor. Landscape heterogeneity and disturbance. Springer-Verlag, New York, New York, USA

Moore, A. D. 1990. The semi-Markov process: a useful tool in the analysis of vegetation dynamics for management. Journal of Environmental Management 30:111-130.

Moore, A. D., and I. R. Noble. 1990. An individualistic model of vegetation stand dynamics. Journal of Environmental Management 31:61-81.

Naveh, Z., and A. S. Lieberman. 1984. Landscape ecology. Theory and application. Springer-Verlag, New York, New York, USA.

Oldeman, R. A. A. 1978. Architecture and energy exchange of dicotyledonous trees in the forest. Pages 535-559 in P. B. Tomlinson and M. Zimmermann, editors. Tropical trees as living systems. Cambridge University Press, Cambridge, UK.

Pastor, J., J. Bonde, C. Johnston, and R. J. Naiman. 1993 Markovian analysis of the spatially dependent dynamics of beaver ponds. Pages 5-27 in R. H. Gardner, editor. Some mathematical questions in biology: predicting spatial effects in ecological systems. Volume 23. Lectures on Mathematics in the Life Sciences. American Mathematical Society, Providence, Rhode Island, USA.

Risser, P. G. 1987. Landscape ecology: state of the art. Pages 3-14 in M. G. Turner, editor. Landscape heterogeneity and disturbance. Springer-Verlag, New York, New York, USA.

Runkle, J. R. 1981. Gap regeneration in some old-growth forests of the Eastern United States. Ecology 62:10411051. 
Scanlan, J. C., and S. Archer. 1991. Simulated dynamics of succession in a North American subtropical Prosopis savanna. Journal of Vegetation Science 2:625-634.

Shugart, H. H. 1984. A theory of forest dynamics: the ecological implications of forest succession models. SpringerVerlag, New York, New York, USA.

- 1987. Dynamic ecosystem consequences of tree birth and death patterns. BioScience 37(8):596-602.

. 1989. The role of ecological models in long-term ecological studies. Pages 90-109 in G. E. Likens, editor Long term studies in ecology. Approaches and alternatives. Springer-Verlag, New York, New York, USA.

Shugart, H. H., T. R. Crow, and J. M. Hett. 1973. Forest succession models: a rationale and methodology for modeling forest succession over large regions. Forest Science 19(3): 203-212.

Shugart, H. H., and D. L. Urban. 1989. Factors affecting the relative abundances of forest tree species. Pages 249-273 in P. J. Grubb and J. B. Whittaker, editors. Toward a more exact ecology. Blackwell Scientific, Oxford, UK.

Shugart, H. H., and D. C. West. 1977. Development of an Appalachian deciduous forest succession model and its application to assessment of the impact of the chestnut blight. Journal of Environmental Management 5:161-179.

Shugart, H. H., D. C. West, and W. R. Emanuel. 1981. Patterns and dynamics of forests: an application of simulation models. Pages 74-94 in D. C. West, H. H. Shugart, and D. B. Botkin, editors. Forest succession concepts and applications. Springer-Verlag, New York, New York, USA.

Smith, A. P., K. P. Hogan, and J. R. Idol. 1992. Spatial and temporal patterns of light and canopy structure in a lowland tropical moist forest. Biotropica 24(4):503-511.

Smith, T. M., and M. Huston. 1989. A theory of the spatial and temporal dynamics of plant communities. Vegetatio 83 : 49-69.

Sprugel, D. G., and F. H. Bormann. 1981. Natural disturbance and the steady state in high-altitude balsam fir forests. Science 211:390-393.

Swaine, M. D., and T. C. Whitmore. 1988. On the definition of ecological species groups in tropical rain forests. Vegetatio 75:81-86.

Tomlinson, P. B. 1987. Architecture of tropical plants. Annual Review of Ecology and Systematics 18:1-21.

Turner, M. G. 1987. Spatial simulation of landscape changes in Georgia: a comparison of three models. Landscape Ecology 1:29-36.

Urban, D. L., G. B. Bonan, T. M. Smith, and H. H. Shugart. 1991. Spatial applications of gap models. Forest Ecology and Management 42:95-110.

Urban, D. L., and H. H. Shugart. 1992. Individual-based models of forest succession. Pages 249-292 in D. C. GlennLewin, R. K. Peet, and T. T. Veblen, editors. Plant succession: theory and prediction. Chapman and Hall, London, UK.

U.S. Army Corps of Engineers. 1991. GRASS. User's and programmer's manual for the Geographic Resource Analysis Support System. USA CERL ADP Report N-87/22.

Usher, M. B. 1979. Markovian approaches to ecological succession. Journal of Animal Ecology 48:413-426.

- 1981. Modeling ecological succession with particular reference to Markovian models. Vegetatio 46:11-18. 1992. Statistical models of succession. Pages 215248 in D. C. Glenn-Lewin, R. K. Peet, and T. T. Veblen, editors. Plant succession: theory and prediction. Chapman and Hall, London, UK.

van Hulst, R. 1979a. On the dynamics of vegetation: succession in model communities. Vegetatio 39:85-96.

- $1979 b$. On the dynamics of vegetation: markov chains as models of succession. Vegetatio 40:3-14.

- 1980. Vegetation dynamics or ecosystem dynamics: dynamic sufficiency in succession theory. Vegetatio 43: 147-151.

Watt, A. S. 1947. Pattern and process in the plant community. Journal of Ecology 35:1-22.

Weinstein, D. A., and H. H. Shugart. 1983. Ecological modeling of landscape dynamics. Pages 29-45 in H. A. Mooney and M. Godron, editors. Disturbance and ecosystems, components of response. Springer-Verlag, New York, New York, USA.

Whitmore, T. C. 1989. Canopy gaps and the two major groups of forest trees. Ecology 70:536-538.

Whittaker, R. H., and S. A. Levin. 1977. The role of mosaic phenomena in natural communities. Theoretical Population Biology 12:117-139.

Wissel, C. 1992. Modelling the mosaic cycle of a Middle European beech forest. Ecological Modelling 63:29-43.

Woodward, F. I. 1987. Climate and plant distribution. Cambridge University Press, Cambridge, UK. 